\title{
Series of Experiments with Thermal Insulation Coatings Consisted of Vacuum-Hollow Nano- Ceramic Microspheres
}

\author{
D. Bozsaky ${ }^{1}$ \\ ${ }^{1}$ Széchenyi István University, Department of Architecture and Building \\ Construction \\ Egyetem tér 1, H-9026 Győr, Hungaryy \\ Phone: +36 96503454 \\ e-mail: bozsaky@gmail.com
}

Abstract: Because of the rigorous regulations in the 21 st century it has become a serious task for designers to find more effective ways for thermal insulation. One of these options is the application of nanotechnologybased materials. Among nano-scale structured materials the most uncertainties are found about the thermal insulating quality of thermal insulation coatings consisted of vacuum-hollow nano-ceramic microspheres. Complete agreement had not been already found about the mechanism of their insulating effect. In order to explore and describe the thermodynamic process inside nano-ceramic coatings (NCC) 6 series of heat transfer resistance experiments were performed in 2014-2017. Several building structure configurations with 12 different orders of layers were tested with a standard heat flow meter. On basis of these results it could be concluded that in case of nanostructured materials convective heat transfer coefficient might be taken account in different way than in case of traditional macro-structured thermal insulation materials.

Keywords: nanotechnology, thermal insulation coating, nano-ceramic

\section{Introduction}

Nowadays, our society is facing major problems of energy and environmental aspects. Rationalizing our energy consumption and promoting the use of materials with low environmental impact are measures to be taken to slow the degradation of 
our environment as well as early exhaustion of available energy resources. The building sector has over $40 \%$ of global energy consumption and $56.7 \%$ in carbon dioxide emissions, which is considerable [1] [2]. Because of these reasons regulations relating to thermal insulation performance of buildings are getting more and more rigorous in the 21 st century. It has become a serious task for designers to find more effective ways for thermal insulation of buildings

The appearance of nanotechnology-based materials in architecture and civil engineering opened several possibilities in the 1990s to use them in building industry. Tensile, shear and bending strength of concrete structures can be strengthened by nanotubes or nanofibers. Nano-silica additives can increase durability and compressive strength of cement-based materials. They can be used to increase fluidity or water permeability of concrete [3] [4]. Wood-based composite materials with nanotube or nanofiber addition could have twice higher stability and mechanical strength as steel [3]. Coatings containing nanoparticle form of titanium dioxide $\left(\mathrm{TiO}_{2}\right)$ is used to build up self-cleaning surfaces [3] [4]. Nanoparticle-based coatings can also provide better adhesion, transparency, corrosion and fire protection [3] [4].

There are also several types of nanotechnology-based thermal insulation materials (e.g.; vacuum insulation panels, aerogel insulations and thermal insulation coatings consisted of vacuum-hollow nano-ceramic microspheres). Such variety of insulating products allows many possibilities to use them effectively in housing. These thermal insulation materials are generally considered to have better thermal insulation quality than traditional materials (e.g.; mineral wool products, plastic foams, etc.). Their nanostructure can hamper one or more ways of heat transport; therefore they can decrease the heat transfer coefficient of building structures [5] [6] [7] [8].

The research conducted at Széchenyi István University between 2014-2017 was intended to study the thermal insulation quality of nano-ceramic thermal insulation coatings in order to give adequate description the thermodynamic process inside its nanostructure. Chapter 2 contains a brief description about history, production and materials characteristics of nano-ceramic coatings. In the first part of Chapter 3 the paper reviews theoretical and experimental results of other authors and researchers. For better understanding, Chapter 3.1 summarizes the former experiments conducted at Széchenyi István University in 2014-2016 and then, Chapter 3.2 presents the new experiments and results. In the end, Chapter 4 contains the conclusions.

\section{Thermal Insulation Coatings Consisted of Hollow Nano-Ceramic Microspheres}

Among nanotechnology-based thermal insulation materials thermodynamic performance of thermal insulation coatings consisted of hollow nano-ceramic 
microspheres generally generates intensive arguments in academic circles because of contradictory technical data that could be found in special literature and in producers' handouts. Complete agreement had not been already found about the mechanism of their insulating effect. Producers state that their excellent thermal insulating quality is due to their extremely low thermal conductivity [9] [10] [11]. Other researchers claim that thermal insulation coatings can highly increase heat transfer resistance of the insulated surface by reducing convective heat transfer coefficient [12]. Experiments have shown that they are able to improve the heat transfer coefficient of solid brick masonry [8].

In the early 1980s, Sridhar Komarneni and Rustum Roy [13] developed the first method of synthetizing nano-ceramics. This process called 'sol-gel' and enabled researchers to test the properties of nano-ceramics [13]. To produce nano-ceramics at a more efficient way this process was later replaced by microwave sintering [14].

The most common paint-on insulation products in Hungary contain microscopic vacuum-hollow ceramic microspheres with a diameter of $20-120 \mu \mathrm{m}$ and with a cellular wall thickness of 50-200 $\mathrm{nm}$. They were made of melted glass or ceramic on high gas-pressure and high temperature $\left(1500{ }^{\circ} \mathrm{C}\right)$. After they cool down, the pressure ends, leaving a vacuum inside the microspheres. Their binding material is a mixture of synthetic rubber and other polymers. The main components are styrene (20\%) and acryl latex (80\%). Styrene guarantees the mechanical strength. Acryl latex makes this material resistant against weather conditions and provides flexibility. Other additives (e.g., biocides, anti-fouling and antifungal materials) make the final product durable and mold-proofed [9] [14] [15].

These coatings are typically used for exterior and interior wall insulation, but they are also suitable for pipe insulation and protection against fire and corrosion. They can be easily transmitted to hard-to-reach places [9] [15].

After mixing the ceramic microspheres with binding material, additives and water, a brush, roller or spray can be used to apply on the surface to be insulated. To assure adequate and uniform coverage, spray and roll techniques are recommended. All surfaces must be clean and free from any contamination before painting. Generally two insulating layers are required, the first of which acts as a primer layer. The drying time of a layer depends on the temperature (at $20^{\circ} \mathrm{C}$, it takes $4-5$ hours). The complete solidification takes 72 hours [9] [15].

\section{Heat Transfer Experiments}

Special literature provides different data about thermal insulation quality of nanoceramic coatings. Moreover, thermodynamic details are extraordinarily contradictory [16] [17]. Some sources provide that their thermal conductivity is 
around $0.001-0.003 \mathrm{~W} / \mathrm{mK}$ based on measurements of university laboratories in Latvia, Russia (Volgograd) and Hungary (Debrecen) [9] [10] [11]. Other sources publish much higher values (from $0.014 \mathrm{~W} / \mathrm{mK}$ to $0.140 \mathrm{~W} / \mathrm{mK}$ ) [6] [7] [8] and more correctly talk about their effective thermal conductivity [8] [12] which contains the internal convective heat transfer coefficient $\left(\mathrm{h}_{\mathrm{i}}\right)$ and external convective heat transfer coefficient $\left(h_{e}\right)$ of the enclosed nanoscale pores inside the nanostructure. These details are often not confirmed by documented laboratory tests or refer to insufficiently introduced experiments [9] [10] [11]. Others calculate thermal conductivity of nano-ceramic coating from heat transfer coefficient (U-value) of a global building structure [8]. Each method has the same problem that it tries to determine thermal conductivity by an indirect way using conventional data and calculation and it does not take in account that physical and chemical processes inside structures in range from 1 to 100 nanometers can occur differently than in traditional macro sizes.

In order to test thermal performance of nano-ceramic coatings energy balance was investigated in periods of heating and also in the summer at external building surfaces using dynamic outdoor testing. Measurements demonstrated that coating consisting of hollow ceramic microspheres has the same thermodynamic properties as a standard facing coating [18] [19]. Spectral emissivity properties and reflective ability of nano-ceramic thermal insulation coatings were also measured with standard infrared spectroscopy and handheld reflection intensity measurement device. Measured data demonstrated that coatings have the same radiant properties as standard building coatings [20] [21]. Based on GOST 23630.2-79 (Russian standard) using an IT- $\lambda-400$ instrument thermal conductivity of nano-ceramic coatings consisted of hollow inorganic microspheres measured to be $0.10-0.18$ $\mathrm{W} / \mathrm{mK}$ and the effective thickness of the thin-film heat-insulation coating was determined at least $5 \mathrm{~mm}$ (that requires application of 4 layers of material at each layer thickness of 1-1.5 mm) [22].

\subsection{Former experiments (Experiment 1, 2, 3 and 4)}

Before describing the new experiments it is necessary to summarize the former results of heat transfer resistance experiments that were performed in the Laboratory of Building Materials and Building Physics at Széchenyi István University (Győr, Hungary) in 2014-2016.

After studying the special literature 4 heat transfer resistance experiments were made to explore and describe the thermodynamic process inside nano-ceramic coatings. Several building structures with different order of layers were tested with a standard heat flow meter. Results of Experiment 1, Experiment 2, Experiment 3 and Experiment 4 were published in 2015-2017 [22] [23] [24]. 
In Experiment 1 five types (Type 1-5) of samples were made from different kind of traditional thermal insulation materials: Expanded PolyStyrene (EPS), eXtruded PolyStyrene (XPS) and Oriented Strand Board (OSB). Sample Type 1 was uncoated and homogeneous, other samples were sprayed with nano-ceramic coating. Thermal conductivity of homogeneous samples and the effective thermal conductivity $\left(\lambda_{\text {eff }}\right)$ of inhomogeneous samples (Type 2-5) were compared and results seemed to show a minor negative effect of nano-ceramic coating to thermal insulation quality. Only XPS samples showed a small positive effect with an insignificant decreasing value [23] [24].

During Experiment 2 thermal conductivity of the pure nano-ceramic coating was measured directly with a standard heat flow meter on samples with a thickness of 20 $\mathrm{mm}$. The average thermal conductivity in air-dry condition was $0.0690 \mathrm{~W} / \mathrm{mK}$. However; this material is practically not used with such thickness, because they are applied as a thin membrane. Therefore it could not be clearly declared that thermal conductivity of this material has the same thermal conductivity if it is used as a very thin membrane [23].

Based on the previous two experiments it was concluded that insulating effect of nano-ceramic thermal insulation coatings is probably not caused by their extremely low thermal conductivity. As it was formerly mentioned, some sources claim that insulating effect of these materials is generated by not their extremely low thermal conductivity (this value is estimated to be $0.014 \mathrm{~W} / \mathrm{mK}$ ) but their high surface heat transfer resistance.

Considering it as a basic concept Experiment 3 and 4 were conducted in 20152016. For these experiments 12 different orders of layers were constructed from $300 \times 300 \mathrm{~mm}$ samples of thermal insulation materials with different thickness. There were coated and uncoated samples; moreover, $100 \times 100 \mathrm{~mm}$ air gap with a thickness of 20 and $30 \mathrm{~mm}$ included into the construction in Experiment 3 and 200x200 mm air gap with a thickness of 20 and $30 \mathrm{~mm}$ in Experiments 4. From these experiments it was expected that there should be significant differences between uncoated and coated samples and larger air gap should cause higher changes in effective thermal conductivity. Results were correspondent for expectations, and it seemed to be proven that insulating effect comes from a relatively high surface heat transfer resistance. However; insulating effect was much lower than previously expected [25].

\subsection{Experiment 5 and Experiment 6}

Previous experiments did not provide adequate description about thermodynamic processes inside nano-cermaic coatings. Only a relatively low thermal insulation effect was detectable. Analysing measurement data of Experiments 1-4 it was 
concluded that probably the size of built-in air gaps were too small. Supposing that in a larger air gap air particles should have more possibility for bulk movements; thereby surface heat transfer resistance can prevail much better and higher differences may arise between coated and uncoated samples new experiments were conducted in 2016-2017 that were called Experiment 5 and Experiment 6.

For Experiment 5 and 6 the same order of layers were constructed from 300x300 mm samples of Thermal Insulation Materials (TIM) with 200x200 mm Air Gap (AG) with a thickness of $50 \mathrm{~mm}$ in Experiment 5 and with a thickness of $80 \mathrm{~mm}$ in Experiment 6. Because of the measuring limits $(120 \mathrm{~mm}$ maximum sample thickness) there were only 4 Types (Types 1-4) of configurations in Experiment 6. There were configurations (Table 1), which contained Nano-Ceramic Coated (NCC) and uncoated samples as well (Type 1-6).

\section{Table 1: Sample types for Experiment 5 and 6}

\begin{tabular}{|l|l|}
\hline Type 1 & AG + TIM \\
Type 2 & AG + NCC + TIM \\
Type 3 & TIM + AG + TIM \\
Type 4 & TIM + NCC + AG + TIM \\
Type 5 & AG + TIM + AG \\
Type 6 & AG + NCC + TIM + NCC + AG \\
\hline
\end{tabular}

Samples were prepared by the manufacturing company that provided only approximate data about the raw material. The composition is patented and manufacturers generally do not give completely accurate details about the product. It could be definitely stated that the examined coating was outside façade insulation. Wide limits $(20-50 \mathrm{~m} / \mathrm{m} \%)$ were given about the ratio of the binder material, but certainly it neared the lower limit because coating was sprayed on the surface of samples and low ratio of binder material is ideal for spray technology.

According to EN 12667:2001 standard Taurus TCA 300 heat flow meter was used for measurements. Because of the inhomogeneous, multi-layer structure heat flow meter was able to determine effective thermal conductivity $\left(\lambda_{\text {eff }}\right)$. Effective thermal conductivity of 3-3 pieces from each type of configurations was measured using 3 different kinds of thermal insulation materials: EPS, XPS and OSB plates. Each sample was measured 3 times. Moreover; sample Types 1-4 were measured in two ways; firstly NCC was on the warm side; secondly NCC was on the cold side. Eventually 270 different measurements were conducted in Experiment 5 and 144 in Experiment 6. Together it means a total number of 414 measurements.

Experiments 5 and 6 were to provide information about thermal insulation ability of NCC. Therefore; the main focus of experiments was the difference in effective thermal conductivity between coated and uncoated samples. Compared to Experiment 3 and 4 the only difference in configurations was the multiple increased 
air gaps. Therefore; measurements of Experiments 5 and 6 were also comparable with the results of Experiment 3 and 4. Because of the increased air gap larger changes were expected in effective thermal conductivity of coated and uncoated samples.

The above assumption has been slightly proved because differences in effective thermal conductivity between coated and uncoated samples were really higher than in Experiment 3. It is well-known that the accuracy of Taurus TCA heat flow meter is up to $5 \%$ and these results might be fluctuations in measurement limits. However, in fact, in $92 \%$ there were no deviation between 3 test results of an individual sample, and in $8 \%$ the difference was only $\pm 0.0002 \mathrm{~W} / \mathrm{mK}$ which means really $0.1-0.3 \%$ accuracy.

Table 2: Results of Experiment 3, 4, 5 and 6 with EPS samples

\begin{tabular}{|c|c|c|c|c|c|c|c|c|c|}
\hline & $\begin{array}{l}\text { Air } \\
\text { Gap }\end{array}$ & $\begin{array}{l}\text { Sym } \\
\text { bol }\end{array}$ & Unit & Type 1 & Type 2 & Type 3 & Type 4 & Type 5 & Type 6 \\
\hline \multirow{12}{*}{ } & \multirow{6}{*}{ 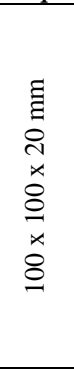 } & $\begin{array}{l}\lambda_{\text {eff,col }} \\
\text { d }\end{array}$ & $\mathrm{W} / \mathrm{mK}$ & 0.06713 & $\begin{array}{c}0.0630 \\
0\end{array}$ & $\begin{array}{c}0.0547 \\
0\end{array}$ & $\begin{array}{c}0.0521 \\
4\end{array}$ & - & - \\
\hline & & $\Delta \lambda_{\text {eff, }}$ & $\%$ & \multicolumn{2}{|c|}{-6.16} & \multicolumn{2}{|c|}{-4.69} & \multicolumn{2}{|c|}{ - } \\
\hline & & $\begin{array}{l}\lambda_{\text {eff,wa }} \\
\text { rm }\end{array}$ & $\mathrm{W} / \mathrm{mK}$ & 0.06691 & $\begin{array}{c}0.0632 \\
3 \\
\end{array}$ & $\begin{array}{c}0.0546 \\
7 \\
\end{array}$ & $\begin{array}{c}0.0520 \\
5\end{array}$ & - & - \\
\hline & & $\begin{array}{l}\Delta \lambda_{\text {eff, }} \\
\text { warm }\end{array}$ & $\%$ & \multicolumn{2}{|c|}{-5.50} & \multicolumn{2}{|c|}{-4.80} & \multicolumn{2}{|c|}{ - } \\
\hline & & $\lambda_{\text {eff }}$ & $\mathrm{W} / \mathrm{mK}$ & 0.06702 & $\begin{array}{c}0.0631 \\
2\end{array}$ & $\begin{array}{c}0.0546 \\
9\end{array}$ & $\begin{array}{c}0.0520 \\
9\end{array}$ & $\begin{array}{c}0,0858 \\
3\end{array}$ & $\begin{array}{c}0,0784 \\
0\end{array}$ \\
\hline & & $\Delta \lambda_{\text {eff }}$ & $\%$ & \multicolumn{2}{|c|}{-5.83} & \multicolumn{2}{|c|}{-4.75} & \multicolumn{2}{|c|}{-8.66} \\
\hline & \multirow{6}{*}{ 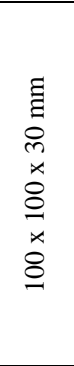 } & $\begin{array}{l}\lambda_{\text {eff,col }} \\
\text { d }\end{array}$ & $\mathrm{W} / \mathrm{mK}$ & 0.08231 & $\begin{array}{c}0.0776 \\
1\end{array}$ & $\begin{array}{c}0.0621 \\
0\end{array}$ & $\begin{array}{c}0.0590 \\
2 \\
\end{array}$ & - & - \\
\hline & & $\Delta \lambda_{\text {eff }}$ & $\%$ & \multicolumn{2}{|c|}{-5.71} & \multicolumn{2}{|c|}{-4.96} & \multicolumn{2}{|c|}{ - } \\
\hline & & $\begin{array}{l}\lambda_{\text {eff,wa }} \\
\text { rm }\end{array}$ & $\mathrm{W} / \mathrm{mK}$ & 0.08312 & $\begin{array}{c}0.0783 \\
0\end{array}$ & $\begin{array}{c}0.0621 \\
2\end{array}$ & $\begin{array}{c}0.0590 \\
5\end{array}$ & - & - \\
\hline & & $\begin{array}{l}\Delta \lambda_{\text {eff, }} \\
\text { warm }\end{array}$ & $\%$ & \multicolumn{2}{|c|}{-5.79} & \multicolumn{2}{|c|}{-4.94} & \multicolumn{2}{|c|}{-} \\
\hline & & $\lambda_{\text {eff }}$ & $\mathrm{W} / \mathrm{mK}$ & 0.08272 & $\begin{array}{c}0.0779 \\
6\end{array}$ & $\begin{array}{c}0.0621 \\
1\end{array}$ & $\begin{array}{c}0.0590 \\
3\end{array}$ & $\begin{array}{c}0.1092 \\
3\end{array}$ & $\begin{array}{c}0.1002 \\
8\end{array}$ \\
\hline & & $\Delta \lambda_{\text {eff }}$ & $\%$ & \multicolumn{2}{|c|}{-5.75} & \multicolumn{2}{|c|}{-4.95} & \multicolumn{2}{|c|}{-8.19} \\
\hline \multirow{3}{*}{ 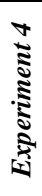 } & \multirow{3}{*}{ 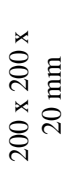 } & $\begin{array}{l}\lambda_{\text {eff,col }} \\
\text { d }\end{array}$ & $\mathrm{W} / \mathrm{mK}$ & 0.06475 & $\begin{array}{c}0.0603 \\
2\end{array}$ & $\begin{array}{c}0.0559 \\
7\end{array}$ & $\begin{array}{c}0.0532 \\
6\end{array}$ & - & - \\
\hline & & $\begin{array}{l}\Delta \lambda_{\text {eff, }} \\
\text { cold }\end{array}$ & $\%$ & \multicolumn{2}{|c|}{-6.84} & \multicolumn{2}{|c|}{-4.85} & \multicolumn{2}{|c|}{-} \\
\hline & & $\begin{array}{l}\lambda_{\text {eff,wa }} \\
\text { rm }\end{array}$ & $\mathrm{W} / \mathrm{mK}$ & 0.06094 & $\begin{array}{c}0.0570 \\
4 \\
\end{array}$ & $\begin{array}{c}0.0559 \\
4 \\
\end{array}$ & $\begin{array}{c}0.0533 \\
7 \\
\end{array}$ & - & - \\
\hline
\end{tabular}




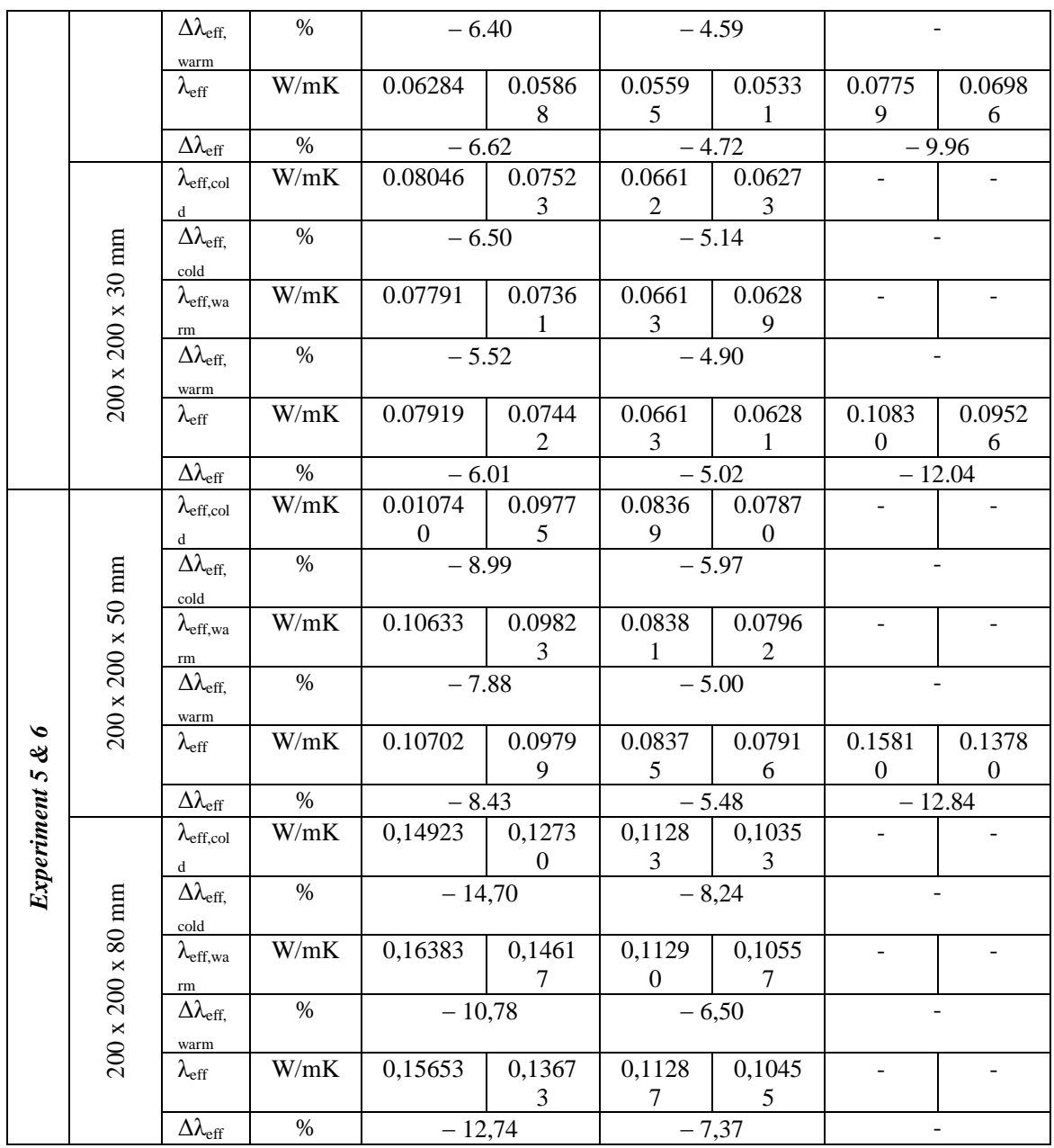

Effective thermal conductivity changes caused by nano-cermaic coating were the most apparent in EPS samples (Table 2). In Experiment 5 the most significant difference in effective thermal conductivity (12.84\%) was found between configuration Type 5 and configuration Type 6 due to the two-sided nano-ceramic coating. As it was formerly expected, higher changes were registered than in Experiment 3 and 4. In case of Types 1-2 change level was also higher $(8.99 \%$ on cold side and $7.88 \%$ on warm side in Experiment 5 and $14.70 \%$ on cold side and $10.78 \%$ on warm side in Experiment 6) than Experiment 3 and 4. Effective thermal conductivity changes were also the lowest in case of Types 3-4 (5.97\% on cold side 
and $5.00 \%$ on warm side in Experiment 5 and $8.24 \%$ on cold side and $6.50 \%$ on warm side in Experiment 6) but despite of Experiment 3 and 4 these values were more significant. This phenomenon can be explained that if an air gap is closed inside two layers of thermal insulation air particles are less able to move and the effect of surface heat transfer resistance becomes smaller. It can be also concluded that the application of NCC in this way could be the least efficient. In Experiment 6 remarkably higher changes were registered that was probably caused by the much thicker $(80 \mathrm{~mm})$ air gap. Contrary to the past experiments there were evincible differences between measurement results depending on the location of the coating (warm or cold side). In former experiments with smaller air gaps (20 and $30 \mathrm{~mm}$ ) effective thermal conductivity was measured the same regardless whether the coating was on the cold or warm side. New results showed that nano-ceramic coating has stronger effect on the cold side.

In case of XPS samples smaller changes can be observed (Table 3) similarly to Experiment 3 and 4. This could be explained by the results of Experiment 1 where nano-ceramic coating itself had resulted reduction of thermal conductivity. This is why surface heat transfer resistance seems to have minor effect on thermal insulation quality. Change of thermal conductivity was the most significant in configuration Types 1-2 $(6.17 \%$ on the cold side and $4.00 \%$ on the warm side in Experiment 5 and $8.91 \%$ on the cold side and $8.90 \%$ on the warm side in Experiment 6). Configuration Types 5-6 showed also higher changes than in Experiment 3 and 4 but the increase was not as significant as in case of EPS samples (4.53\%). Just like EPS samples, a little bit lower changes were measured in case of Types 3-4 $(3.73 \%$ and $2.38 \%$ in Experiment 5, and 5.02\% and 3.49\% in Experiment 6). There were also similar detectable differences to EPS samples between measurement results depending on the location of the coating (warm or cold side).

Table 3: Results of Experiment 3, 4, 5 and 6 with XPS samples

\begin{tabular}{|c|c|c|c|c|c|c|c|c|c|}
\hline & $\begin{array}{l}\text { Air } \\
\text { Gap }\end{array}$ & $\begin{array}{l}\text { Symb } \\
\text { ol }\end{array}$ & Unit & Type 1 & Type 2 & Type 3 & Type 4 & Type 5 & Type 6 \\
\hline \multirow{7}{*}{ 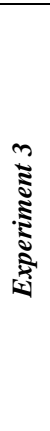 } & \multirow{6}{*}{ 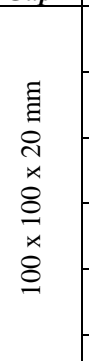 } & $\lambda_{\text {eff,cold }}$ & $\begin{array}{c}\mathrm{W} / \mathrm{m} \\
\mathrm{K}\end{array}$ & $\begin{array}{c}0.0514 \\
8 \\
\end{array}$ & $\begin{array}{c}0.0496 \\
4\end{array}$ & $\begin{array}{c}0.0453 \\
4 \\
\end{array}$ & $\begin{array}{c}0.0436 \\
9\end{array}$ & - & - \\
\hline & & $\Delta \lambda_{\text {eff,col }}$ & $\%$ & \multicolumn{2}{|c|}{-3.57} & \multicolumn{2}{|c|}{-3.64} & \multicolumn{2}{|c|}{ - } \\
\hline & & $\lambda_{\text {eff,warm }}$ & $\begin{array}{c}\mathrm{W} / \mathrm{m} \\
\mathrm{K}\end{array}$ & $\begin{array}{c}0.0513 \\
9 \\
\end{array}$ & $\begin{array}{c}0.0496 \\
8 \\
\end{array}$ & $\begin{array}{c}0.0457 \\
8 \\
\end{array}$ & $\begin{array}{c}0.0442 \\
5\end{array}$ & - & - \\
\hline & & $\begin{array}{l}\Delta \lambda_{\text {eff,wa }} \\
\text { rm }\end{array}$ & $\%$ & \multicolumn{2}{|c|}{-3.33} & \multicolumn{2}{|c|}{-3.34} & \multicolumn{2}{|c|}{ - } \\
\hline & & $\lambda_{\text {eff }}$ & $\begin{array}{c}\mathrm{W} / \mathrm{m} \\
\mathrm{K}\end{array}$ & $\begin{array}{c}0.0514 \\
4\end{array}$ & $\begin{array}{c}0.0496 \\
6\end{array}$ & $\begin{array}{c}0.0455 \\
6\end{array}$ & $\begin{array}{c}0.0439 \\
7\end{array}$ & $\begin{array}{c}0.0645 \\
6\end{array}$ & $\begin{array}{c}0.0627 \\
6\end{array}$ \\
\hline & & $\Delta \lambda_{\text {eff }}$ & $\%$ & \multicolumn{2}{|c|}{-3.45} & \multicolumn{2}{|c|}{-3.49} & \multicolumn{2}{|c|}{-2.79} \\
\hline & -0 & $\lambda_{\text {eff,cold }}$ & $\begin{array}{c}\mathrm{W} / \mathrm{m} \\
\mathrm{K}\end{array}$ & $\begin{array}{c}0.0623 \\
3\end{array}$ & $\begin{array}{c}0.0602 \\
1\end{array}$ & $\begin{array}{c}0.0505 \\
3\end{array}$ & $\begin{array}{c}0.0487 \\
4\end{array}$ & - & - \\
\hline
\end{tabular}


D. Bozsaky - Acta Technica Jaurinensis, Vol. 11, No. 1, pp. 17-33, 2018

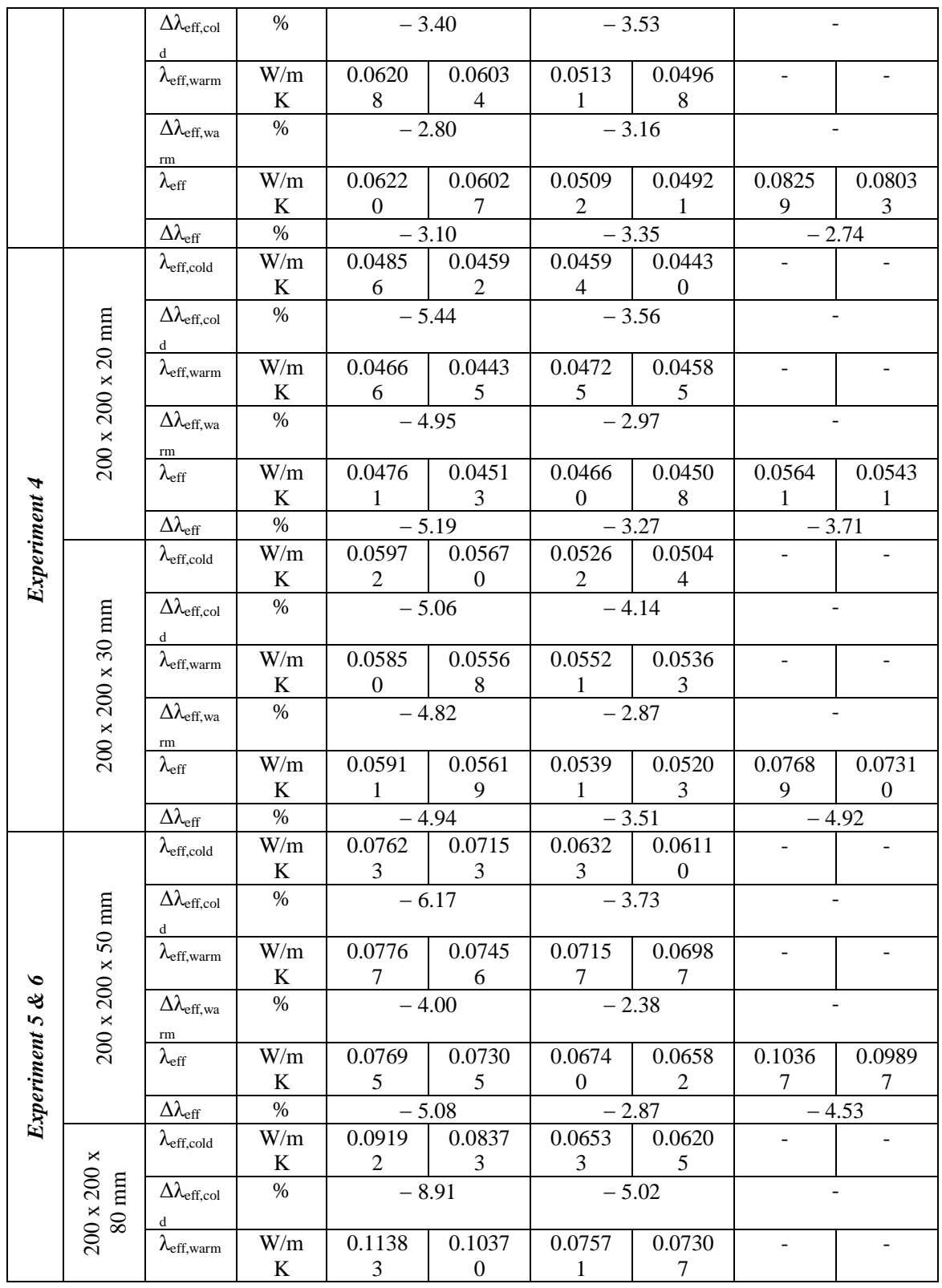




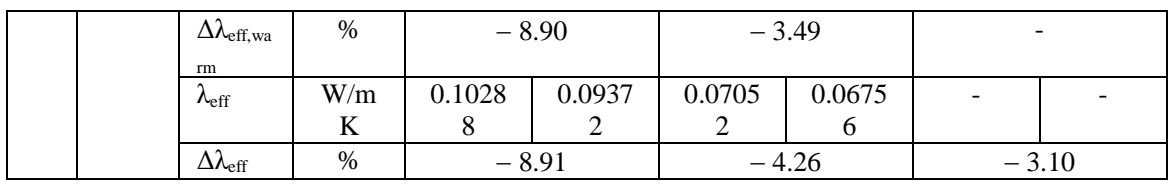

In case of OSB boards insulating effect of nano-ceramic coating was undetectable (Table 4). Except sample Types 5-6, all measurements showed that coating has a negative effect on thermal insulation quality. It can be observed that this negative effect decreases by increasing the thickness of the air gap. Analyzing the results of Types 3-4 it can be observed that in case of $20 \mathrm{~mm}$ air gap NCC increased effective thermal conductivity with $2.82 \%$ in Experiment 3, and 3.08\% in Experiment 4. With $30 \mathrm{~mm}$ air gap this value was $2.83 \%$ in Experiment 3 (it is nearly the same) but $2.68 \%$ in Experiment 4. In Experiment 5 this value decreased to $1.88 \%$ and in Experiment 6 to $1.05 \%$. Measurement results of Types 5-6 show that with two-sided $20 \mathrm{~mm}$ air gap NCC increased effective thermal conductivity with $2.29 \%$ in Experiment 3 and $2.16 \%$ in Experiment 4 . With $30 \mathrm{~mm}$ air gap this value decreased to $1.21 \%$ in Experiment 3 and to $-0.02 \%$ (i.e.; nearly zero) in Experiment 4 . Using $50 \mathrm{~mm}$ air gap a very small decreasing of effective thermal conductivity was detected $(-1.04 \%)$.

On basis of these results it could be concluded that NCC requires a much larger air gap in order to have beneficent thermal insulation effect on OSB plates. It can be also admitted that thermal insulation effect of NCC could be very different on different types of surfaces.

Table 4: Results of Experiment 3, 4, 5 and 6 with OSB samples

\begin{tabular}{|c|c|c|c|c|c|c|c|c|c|}
\hline & $\begin{array}{l}\text { Air } \\
\text { Gap }\end{array}$ & $\begin{array}{l}\text { Symb } \\
\text { ol }\end{array}$ & Unit & Type 1 & Type 2 & Type 3 & Type 4 & Type 5 & Type 6 \\
\hline \multirow{9}{*}{ 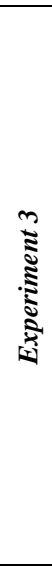 } & \multirow{6}{*}{ 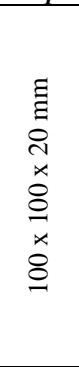 } & $\lambda_{\text {eff,cold }}$ & $\begin{array}{c}\mathrm{W} / \mathrm{m} \\
\mathrm{K}\end{array}$ & 0.10517 & 0.10910 & $\begin{array}{c}0.0667 \\
4\end{array}$ & $\begin{array}{c}0.0684 \\
5\end{array}$ & - & - \\
\hline & & $\begin{array}{l}\Delta \lambda_{\text {eff,c }} \\
\text { old }\end{array}$ & $\%$ & \multicolumn{2}{|c|}{+3.74} & \multicolumn{2}{|c|}{+2.57} & \multicolumn{2}{|c|}{ - } \\
\hline & & $\begin{array}{l}\lambda_{\text {eff,war }} \\
\mathrm{m}\end{array}$ & $\begin{array}{c}\mathrm{W} / \mathrm{m} \\
\mathrm{K}\end{array}$ & 0.10743 & 0.11033 & $\begin{array}{c}0.0694 \\
6 \\
\end{array}$ & $\begin{array}{c}0.0716 \\
0\end{array}$ & - & - \\
\hline & & $\Delta \lambda_{\text {eff,w }}$ & $\%$ & \multicolumn{2}{|c|}{+2.70} & \multicolumn{2}{|c|}{+3.08} & \multicolumn{2}{|c|}{ - } \\
\hline & & $\lambda_{\text {eff }}$ & $\begin{array}{c}\mathrm{W} / \mathrm{m} \\
\mathrm{K}\end{array}$ & 0.10630 & 0.10972 & $\begin{array}{c}0.0681 \\
0\end{array}$ & $\begin{array}{c}0.0700 \\
3\end{array}$ & $\begin{array}{c}0.1180 \\
0\end{array}$ & $\begin{array}{c}0.01207 \\
0\end{array}$ \\
\hline & & $\Delta \lambda_{\text {eff }}$ & $\%$ & \multicolumn{2}{|c|}{+3.22} & \multicolumn{2}{|c|}{+2.82} & \multicolumn{2}{|c|}{+2.29} \\
\hline & \multirow{3}{*}{ 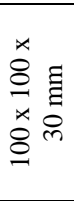 } & $\lambda_{\text {eff,cold }}$ & $\begin{array}{c}\mathrm{W} / \mathrm{m} \\
\mathrm{K}\end{array}$ & 0.12597 & 0.12827 & $\begin{array}{c}0.0734 \\
7 \\
\end{array}$ & $\begin{array}{c}0.0757 \\
1 \\
\end{array}$ & - & - \\
\hline & & $\begin{array}{l}\Delta \lambda_{\text {eff,c }} \\
\text { old }\end{array}$ & $\%$ & \multicolumn{2}{|c|}{+1.83} & \multicolumn{2}{|c|}{+3.04} & \multicolumn{2}{|c|}{ - } \\
\hline & & $\begin{array}{l}\lambda_{\text {eff,war }} \\
\mathrm{m}\end{array}$ & $\begin{array}{c}\mathrm{W} / \mathrm{m} \\
\mathrm{K}\end{array}$ & $\begin{array}{c}0.01272 \\
3 \\
\end{array}$ & 0.13093 & $\begin{array}{c}0.0775 \\
6\end{array}$ & $\begin{array}{c}0.0796 \\
0 \\
\end{array}$ & - & - \\
\hline
\end{tabular}


D. Bozsaky - Acta Technica Jaurinensis, Vol. 11, No. 1, pp. 17-33, 2018

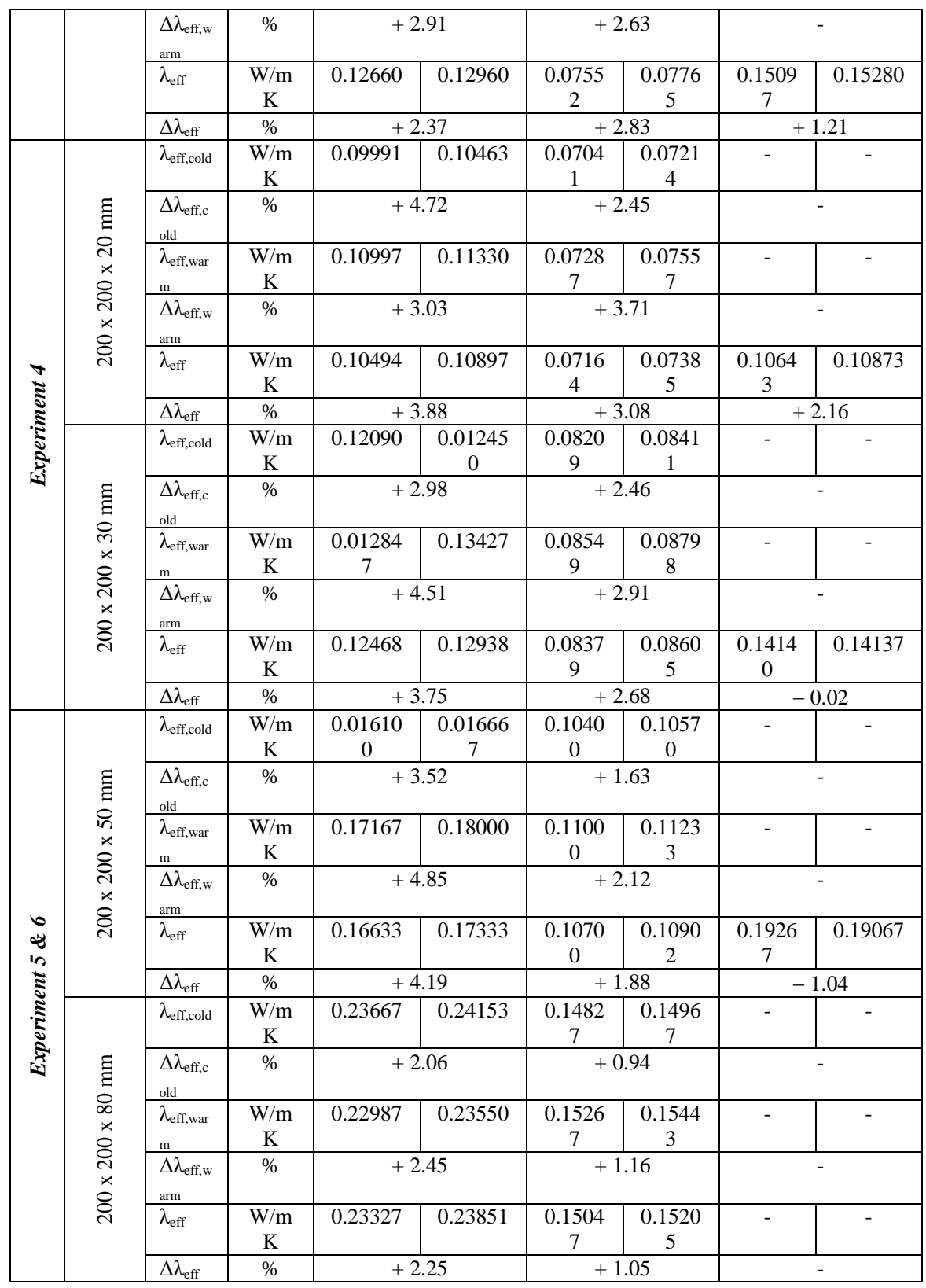




\section{Discussion}

Nano-ceramic coatings cause plenty of scientific discussion between architects because there is no accepted consensus about their thermal insulating quality. In addition, a wide variety of manufacturers and distributors provide contradictory material properties in their product brochures. Manufactureres generally do not explain how material properties are measured and they often do not refer scientifically accepted special literature. They also do not give satisfying information about material composition; therefore it is often difficult to decide exactly which type of material is involved [9] [10] [11].

Numerous theoretical and experimental researches have been conducted in the past few years and results have raised several questions. Researchers did not reveal any difference between thermal insulation quality of conventional paints and nanoceramic coatings with energy balance calculations, spectral emissivity and reflective ability measurements of nano-ceramic thermal insulation coatings [18] [19] [20] [21]. Thermal conductivity was indirectly calculated from measurements of heat transfer coefficient but obtained values were quite different $(0.00177 \mathrm{~W} / \mathrm{mK}$ and $0.10-0.18 \mathrm{~W} / \mathrm{mK}$ ) [9] [11] [22].

Some theoretical papers explain thermal insulating ability of nano-ceramic coatings not with its low thermal conductivity, but with its high surface heat transfer resistance. These papers claim that as a result of the nanostructure, heat transfer process on the inside and outside surface of nano-ceramic coating becomes different from traditional macrostructured materials and internal and external surface heat transfer coefficient recommended by the standards $\left(h_{i}=8 \mathrm{~W} / \mathrm{m}^{2} \mathrm{~K}\right.$ and $h_{e}=$ $24 \mathrm{~W} / \mathrm{m}^{2} \mathrm{~K}$ ) have to be changed [6] [7] [12] [17].

Former laboratory tests (Experiment 1 and Experiment 2) conducted in 2014-2015 in the Laboratory of Building Materials and Building Physics at Széchenyi István University showed that nano-ceramic thermal insulation coatings probably do not have an extremely low thermal conductivity that was described by the available documents of producers and distributors. Their thermal conductivity is likely to be higher than that of traditional thermal insulation materials like mineral wool products or plastic foams (e.g. EPS, XPS and polyurethane foam) [23].

Former thermodynamic experiments (Experiment 3 and Experiment 4) in 20142016 were partially seemed to prove the hypothesis of some special literature sources that insulating effect of nano-ceramic coatings comes from a relatively high surface heat transfer resistance because in some sample configurations, where an air gap was inserted, effective thermal conductivity of coated samples was lower than the uncoated samples. These results based the following series of measurements that were conducted in 2016-2017[24] [25]. 


\section{Conclusions}

New series of thermodynamic experiments (Experiment 5 and Experiment 6) in the Laboratory of Building Physics and Building Materials at Széchenyi István University (Györ, Hungary) were conducted to prove or disprove the hypothesis of high surface heat transfer resistance. However; it can be seen that the difference of effective thermal conductivity between coated and uncoated samples were getting more significant when the size of the air gap is increasing.

It can be observed that in the case of a surface from low-density material (e.g.; EPS), 50-80 mm air gap might have a significant effect (8.99-14.70\%). When NCC is applied on a surface with medium density (e.g.; XPS) thicker air gap is needed. Applying it on a high-density surface (e.g.; OSB plate) NCC has positive effect on effective thermal conductivity only with two-sided $80 \mathrm{~mm}$ air gap material. Presumably with an infinite air gap (e.g.; on the outside surface of masonry structure) insulating effect of NCC would be much more intensive.

Experiments 5 and 6 confirmed the former assumption based by Experiment 4 that higher heat transfer resistance of coated samples caused by the lower surface convective heat transfer coefficient. It can be declared that in case of nano-structured materials convective heat transfer coefficient might be taken account in different way than in case of traditional macro-structured thermal insulation materials.

Test results also showed that thermal insulating ability of this material prevails otherwise on different kind of surfaces. Insulation effect depends not only on the thickness of the air gap but also on the material of the insulated surface. Presumably the same material quality, composition and application technology may not be suitable for insulating different kind of surfaces. Every time we need to find correct solution and definitely the same material is not suitable for all surfaces.

Further studies are needed to have quantified data about the insulation effect of NCC. It would be important to make in-situ heat transfer experiments (Experiment 7) with NCC for better understanding the thermal insulation behavior of it. In order to achieve this goal heat transfer coefficient of several sample buildings should be measured without any thermal insulation. These basic data should be compared with the heat transfer coefficient of structures with NCC insulation. Based on previous (Experiments 1-6) and future tests (Experiment 7) a specific value of external and internal convective heat transfer coefficient (he and hi) should be calculated. Experiments and analysis are still running. Results will be reported in a subsequent study. 


\section{Acknowledgement}

The author would like to acknowledge and thank the financial support of the project EFOP-3.6.1-16-2016-00017 - Internationalisation, initiatives to establish a new source of researchers and graduates, and development of knowledge and technological transfer as instruments of intelligent specialisations at Széchenyi István University.

\section{References}

[1] R. Belakroun, A. Gherfia,Y. Kerboua, M. Kadja, T. H. Mai, C. Maalouf, B. Mboumba-Mamboudou,M. T'kint, Experimental investigation of mechanical and thermal properties of a new biosourced insulation material, International Scientific Journal of Environmental Science 4 (2015) pp. 78-81.

[2] A. Shea, M. Lawrence, P. Walker, Hygrothrermal performance of an experimental hemp-lime building, Construction and Building Materials 36 (2012) pp. 270-275.

doi: 10.1016/j.conbuildmat.2012.04.123

[3] F. Pacheco-Torgal, S. Jalali, Nanotechnology: Advantages and drawbacks in the field of construction and building materials, Construction and Building Materials 25 (2) (2011) pp. 582-590.

doi: 10.1016/j.conbuildmat.2010.07.009

[4] M. Abdelrahman, Towards sustainable architecture with nanotechnology, AlAzhar Engineering 11th International Conference, Cairo, Egypt, 21-23 December 2010, paper 154 .

[5] P. B. Jelle, A. Gustavsen, S. Grynning, E. Wegger, E. Sveipe, R. Baetens, Nanotechnology and Possibiles for the Thermal Building Insulation Materials of Tomorrow, In: Haase M., Hestnes A. G. (Eds), Renewable Energy Research Conference 2010 - Zero Emission Buildings, 7-8 June 2010, Trondheim (Norway), Norwegian University of Science and Technology \& Tapir Academic Press, ISBN 978-82-519-2623-2, 2010, pp. 121-132.

[6] J. Orbán, Use of nanotechnology in building industry, Part I. (in Hungarian), Magyar Építéstechnika 50 (1) (2012) pp. 40-43.

[7] J. Orbán, Use of nanotechnology in building industry, Part II. (in Hungarian), Magyar Építéstechnika 50 (2-3)(2012) pp. 54-57. 
[8] Á. Lakatos, Examination of nanotechnology-based thermal insulation materials on solid brick masonry (in Hungarian), Energiagazdálkodás 57 (34)(2016) pp. 21-25.

[9] Thermogát Ltd.: Thermal insulating process of TSM Ceramic coating; Thermogát Ltd., Budapest (Hungary) [cited 2017-05-14] URL http://tsmceramic.com/?modul=oldal \& tartalom=1196370

[10] Thermo-Shield Inc.: Exterior wall coats, SPM Thermo-Shield Inc., Naples (Florida, United States) [cited 2017-05-05]

URL http://www.thermoshield.com/index.html/thermoshieldexteriorwall.html

[11] MANTI Ceramic Ltd.: Thin-layer thermal protection (in Hungarian), MANTI Ceramic Ltd., Budaörs (Hungary), 2016, p. 20 [cited 2017-05-14] URL https://www.manti.hu/press

[12] J. Orbán, Reducing energy consumption of buildings with the help of thin heat protection coatings, Part II (in Hungarian), Magyar Építéstechnika 9 (2015) pp. 40-42.

[13] D. Hoffman, R. Roy, S. Komarneni, Diphasic ceramic composites via a solgel method, Materials Letters 2 (3) (1984) pp. 245-247. URL https://doi.org/10.1016/0167-577X(84)90035-1

[14] L. I. C. Sandberg, T. Gao, B. P. Jelle, A. Gustavsen, Synthesis of hollow silica nanospheres by sacrificial polystyrene templates for thermal insulation applications, Advances in Material Science and Engineering (2013) p. 6. Article ID 483651

URL http://dx.doi.org/10.1155/2013/483651

[15] W. Lan. F. Kexing, Y. Liang, W. Botao, The application of ceramic coatings in petroleum chemical and building industries, International Conference on Material and Environmental Engineering, 21-24 March 2014, Jiujiang (Jiangxi, China), Atlantis Press, pp. 146-149 doi: 10.2991/icmaee-14.2014.39

[16] G. Paul, M. Chopkar, I. Manna, P. K. Das, Techniques for measuring the thermal conductivity of nanofluids, A Review, Renewable and Sustainable Energy Reviews 14 (7) (2010) pp. 1913-1924. doi: https://doi.org/10.1016/j.rser.2010.03.017 
[17] P. Koniorczyk, J. Zmywaczyk, M. Kowalski, Experimental studies of thermal conductivity of the composite coating consisted of hollow ceramic microspheres, In: Walczok W. (Ed.): 1st Scientific International Coating Congress, 4-5 November 2004, Berlin (Germany), p. 15.

[18] M. Čekon, Thermodynamic Properties of Reflective Coatings, Advanced Materials Research 649 (2013) pp. 179-182 doi: 10.4028/www.scientific.net/AMR.649.179

[19] M. Čekon, M. Kalousek, J. Hraška, R. Ingeli, Spectral optical properties and thermodynamic performance of reflective coatings in a Mild Climate Zone, Energy and Buildings 77 (2014) pp. 343-354. doi: https://doi.org/10.1016/j.enbuild.2014.04.005

[20] M. Čekon, Spectral emissivity properties of reflective coatings, Slovak Journal of Civil Engineering 20 (2) (2012) pp. 1-7. doi: https://doi.org/10.2478/v10189-012-0007-6

[21] L. Ádám, B. Nagy, R. Nemes, Laboratory experiments and development possibilities of reflective coatings (in Hungarian), Megtérülö Épületenergetika 3 (7) pp. 35-39.

[22] V. Y. Chukhlanov, T. A. Trifonova, O. G. Selivanov, M. E. Ilina, N. V. Chukhlanova, Thin-Film Coatings Based on Hollow Inorganic Microsheres and Polyacrilic Binder, International Journal of Applied Engineering Research 12 (7) (2017) pp. 1194-1199.

[23] D. Bozsaky, Laboratory test with liquid nano-ceramic thermal insulation coating, Procedia Engineering 123 (2015) pp. 68-75. doi: https://doi.org/10.1016/j.proeng.2015.10.059

[24] D. Bozsaky, Thermodynamic tests with nano-ceramic thermal insulation coatings, Pollack Periodica 12 (1) (2017) pp. 135-145. doi: https://doi.org/10.1556/606.2017.12.1.11

[25] D. Bozsaky, Heat transfer resistance experiments of thermal insulation coatings consisted of hollow nano-ceramic microspheres, In: NANOTEK 2017 Bioleagues Worldwide Conference, 11-13 March 2017, Hamburg (Germany), ISBN 978-81-932966-1-5, 2017, pp. 9-18. 